\title{
The IT Audit Objective Research Based on the Information System Success Model under the Big Data Environment
}

\author{
Tingliao $\mathrm{Li}^{1,2, \text { a }}$, Lianghua Chen ${ }^{1}$ \\ ${ }^{1}$ Southeast Univ, Sch Econ \& Management, Nanjing, Jiangsu, Peoples R China \\ ${ }^{2}$ Nanjing Audit University, Jiangsu Nanjing, China \\ atingliao@263.net
}

\begin{abstract}
Information system under the big data environment has the characteristics of Volume, Velocity, Variety and Value. Currently, the information system audit objective mainly starting from the characteristics of information system itself, less combined with the specific business objectives. In this paper, Analyzed the influence of the information system under the condition of big data, as well as the potential risks, put forward the information system audit target system based on information system success model (D\&M model).
\end{abstract} risk.

Keywords-information system success model; IT audit; IT

\section{INTRODUCTION}

The data on the Internet data centers in the United States, points out that the Internet will grow by $50 \%$ a year, will double every two years. The data more than $90 \%$ produced in recent years. The big data praised as "the third wave of reality" by the famous futurist alvintoffler in the "third wave" in 1980. Starting around 2009, "big data" become a hot topic of Internet information technology industry.

\section{A. Big data influence}

Gartner give a definition of "Big data" as: "the big data" is the need to deal with the new model can have better decision-making, insight found mass force and the process optimization ability, high rate of growth and diversification of information assets, the big data has the characteristic as Volume, Velocity ,velocity and Value .From the point of view of data categories, big data is unable to use traditional processes and tools for processing or analytical information, refers to those beyond normal processing and size, forcing users to use non-traditional methods of data sets. Big data may not contain all the information, but includes most of the information.

In the era of big data, because the more data and the efficient analysis tools and algorithms, the user can analyze more data, and possibly deal with all the data associated with a particular phenomenon, rather than rely on random sampling; Huge amounts of data that analysts no longer keen on the accuracy of the data; we can find more potential relationship.

\section{B. Information system characteristics and risk in big data environment}

The characteristics of the information system in large data environment mainly reflected in four aspects: firstly, the data size is large. Usually, large scale of data set is in commonly $10 \mathrm{~TB}$, but in practice, many corporate users put multiple information system data sets together, has formed the petabytes of data; secondly, according to the categories of data from a variety of different business system data source, data types and formats increasingly rich, broke through the previous limit of structured data category, include the half structured and unstructured data; Third, data processing is fast. Under the large amount of data, it can be processed in real-time for the optimization algorithm; Fourth, data authenticity is high. With the rise of new data sources such as social data, enterprise content, transaction and application, the limitations of traditional data source is broken. Then we can ensure the authenticity of information and information security through cross validation.

Big data brought great change to our life, study, work, entertainment, etc. all kinds of organizations and departments pay more attention to the depth value of data resource, to meet the requirement of increasing sophistication, scientific management.

For example, the public sector through large data can provide better service for citizens' daily life, realize the weather, food security, traffic, and all kinds of public information of public life, improve the level of management coordination ability and management decision making; The private sector (enterprise) can use the big data generated from daily operation, in-depth digging and analysis the behavior of people intention, found the hided regularity of data , and precise positioning target market and customer , marketing, promotion, and forecast and other activities.

While changing People's Daily life style, work habits and thinking models, big data also brought new risks. Such as safety risk in the collection, storage and use process of the big data; Privacy leaks as a result of big data; incorrect or invalid of big data analysis led by false data, etc. [1].

\section{Data management problems in big data environment}

With the rapid growth of data supply, how to conduct effective management for large data, increasing the data use 
value, becomes an urgent issue to be solved. The current data management problems are mainly shown as follows.

\section{1) Not fully play the data resource value}

In the information service supply, about $80 \%$ domestic social information resources are controlled by the government as a result of the government dominant position in data resource development, IS construction and related investment. In this case, some management departments have mistaken data ownership as power ownership, not willing to share the data resource online; Part of industries(departments) developed online data service system solely by their own will, causing a serious waste of resources, such as insufficient, repeat and idle information products. In more than 3000 existing databases in the country, less than $10 \%$ are really disseminated and used. The value of public information failed to effectively play.

2) Lack of safety awareness in data management

For the lack of safety awareness in data management, Information has long been used as assets, not realizing the information itself is a resource. Under this concept, actual demand for protection of information system and security awareness often can not match, causing the accident about information leaks occur repeatedly.

3) Not unified data resource standard

With 20 years the government informationization, although a lot of financial funds have been invested, abundant data resources cannot be shared yet due to 'information islands', which is led by the lack of unified and permanent management coordination mechanism, lack of data resource management related laws and lack of management departments at all levels of different standards.

\section{INFORMATION SYSTEM SUCCESS MODEL}

\section{A. The present situation of information system applications}

The business value of information technology is an important management research issue. Business investment in information technology has increased year by year, according to the 2014 Gartner global IT spending report, compared with 2013, in 2014 the global IT spending grew $3.2 \%$, to $\$ 3800$ billion. The Asia Pacific area, compared with 2013, in 2014 the global IT spending grew 4.4\%, to $\$ 759$ billion, of which India up to $9.4 \%$, China $7 \%$. Enterprise software market grows fastest in various types of IT investment, compared with 2013, global investment grows 6.9\%in 2014 ,up to $\$ 320$ billion.

In contrast to the rapid growth of enterprise information technology investment scale, information technology project has a high failure rate, which has become a high risk of the investment in enterprise."The productivity paradox" between high investment and low return in Information technology project has been the practical and academic concern.

How to judge whether the information system is success, is a common concern of internal and external organization stakeholders. Accurate identification of problems in the application of information system, is the first step to solve the problem, is a valid path to improve the competitiveness of enterprises as well. The earlier standard of information system success is mainly focus on whether the information system can run normally, which is from a single point of information system function, usually deviating from the financial performance. Later the use of Balanced Scorecard as the strategic management tool for comprehensive evaluation, or the use of COBIT, ITIL and other relevant international standards fora comprehensive evaluation of information system construction, gradually developed.

\section{B. The evolution of the information system success model}

Evaluation of information system success is a long-term concerned problem in the field of information system. Zani firstly put forward the concept of key success variables, who pointed out that the key variables is factors and the tasks in decision whether organizational successful or not [2]. Subsequently, Rockart first proposed the concept of the critical success factors, who pointed out that the managers must grasp successfully some limited key areas, which should pay special and continuous attention on [3]. Later scholars have launched the research on the key success factors [4].

In the theory of the various models of IS success, the greatest impact is the D\&M model proposed by DeLone and McLean, who initially divides many factors influencing IS success into 6 classes ,namely information quality, system quality, system use, user satisfaction, personal influence and organizational effects. Their study provided a theory framework for the research of IS success, and established theoretically the relationship between these 6 factors, providing space for further research [5]. Delone\&Mclean model (Fig.1) which is summed up by DeLone and McLean is widely accepted by latter researchers.

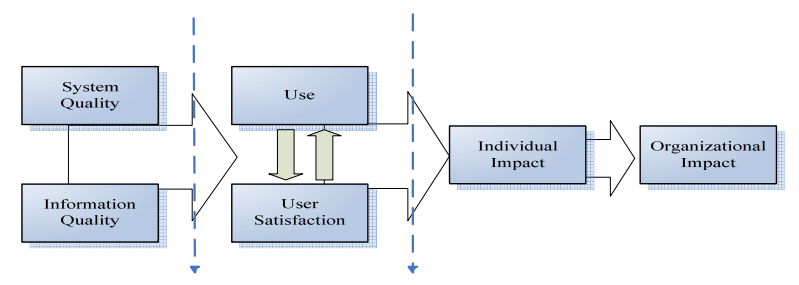

Figure 1. DeLone and McLEAN model 1992

Delone and Mclean divided information systems success evaluation into three parts, the first part is of its own characteristic evaluation system, using the system quality and information quality index; the second part is about system using, measured by the use of the system and the user satisfaction; the third part is of the result of system application, evaluated by personal influence and organizational impact. Since then, the D\&M model is often taken for the study of information system evaluation as the frame of thinking.

In 2003, Deloneand Mcleanmodified the model into a new version (Figure 2), with the service quality introduced into the model, in parallel with the system quality, information quality, commonly influencing system use and user satisfaction, merging people impact and organization 
influence into net income, expanding the measure range. The above net benefits include not only the influence of personal influence and organizational, also includes other effects produced by the system, such as the social influence. The modified model also added the feedback effect of net benefit on system use and user satisfaction model. The improved D\&M model provides a comprehensive framework for thinking, helpful to evaluate the performance of information construction[6].

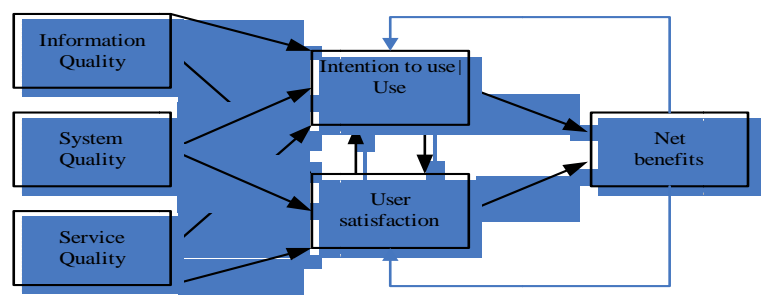

Figure 2. Updated D\&M is success Model 2003

The new model will determine whether the information system successful or not, divided into three stages. The first stage is about whether the system is reliable, whether the operation is normal, how about the safety extent; the second stage is about user satisfaction, using frequency and whether the system provides enough information; the third stage is about whether the use of information system really produces the value, whether the value is a longterm or not, whether the value processing can be sustained. According to the above stage about judging system success, we can convert it into different corresponding audit targets.

\section{INFORMATION SYSTEM AUDIT BASED ON THE INFORMATION SYSTEM SUCCESS MODEL}

\section{A. Information system audit}

Information system audit is the process of evidence collection and evaluation, make judgment whether the information system can safety the assets and maintain data integrity, to effectively implement the target of the business, make the organization's resources efficient use.

Information system audit focuses on information system risk and control measures in the organization. in currently, risks of information system mainly can be divided into three categories from the point of impact: IT capability risk; IT project risk and the risk of IT applications. IT capability risks related to business goals, focus on whether information system effectively and achieve business goals, related to information systems performance evaluation; IT project risk, focusing on specific whether IT project late, over budget, or the function insufficient; The IT applications risk mainly focus on the problem of the concrete operation maintenance, such as security, reliability, etc.

\section{B. The general targe of IT audit}

The COBIT Guide(control objects of information and related technology) ,which put forward by ISACA(information system assurance and audit association), is widely accepted as standard and guideline of information system audit. The guidelines put forward the information system audit objectives include information system effectiveness, efficiency, confidentiality, integrity, availability, consistency, reliability. Involves the resources about the people, architecture, information, and application[7].

The determination of the audit goal mainly from the characteristics of information system itself, suitable for general control audit of information systems audit. But seldom from the view of the auditees business needs to consider the success of information system, which often causes the audit target deviates from the auditees business objectives, leading to the audit found that can not get the attention they deserve, lack of specific audit suggestion.

\section{The IT audit objective based on information system success model}

The essence of Audit is evaluation, and the premise of evaluation is the standard. To evaluate the overall situation of organization information system, it is necessary to consider the construction of information system, the use case of information system, and whether the information system application brings benefits to the organization. Therefore, the use of D\&M model for information audit, is helpful to objectively, comprehensively, continuously evaluate information systems, and also helpful to give targeted audit recommendations.

According to the D\&M model, the evaluation of information system can be divided into three stages, evaluation according to the system, evaluation according to the use of the system and evaluation of the system benefit. The concrete contents including:

(1) On system itself quality audit, including the evaluation of information quality, system quality and service quality.

(2) On system usage audit, including the evaluation of system use effect and user satisfaction.

(3) On business performance audit, including the evaluation of the long-term and short-term performance.

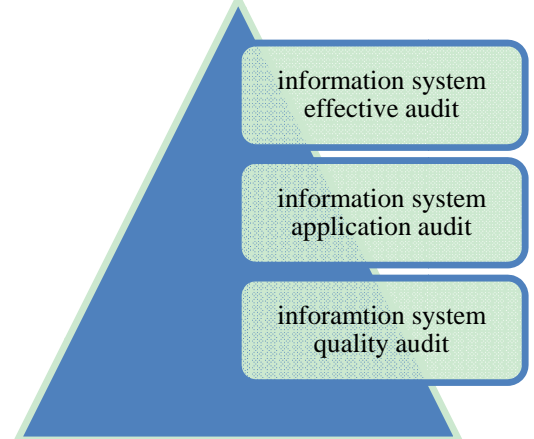

Figure 3. The content of Information system audit based on D\&M model

\section{CONCLUSIONS}

The information system audit target based on D\&M model can comprehensively and systematically response information system quality and using impact, combined with 
the actual situation of business objective to evaluate information system.

\section{ACKNOWLEDGEMENTS}

The research work was supported by Natural Science Foundation of Jiangsu Provincial under grant No. 12KJA630001 and Open Foundation of Jiangsu Audit Information Engineer lab Grant No.AIE201207. AIE201208.

\section{REFERENCES}

[1] Dengguo Feng, Min Zhang, Hao Li. Big data security and privacy protection, computer science [J] 2014(01):246-258.

[2] Zani William M. Blueprint for MIS [J]. Harvard Business Review, 1970(11).
[3] Rockart J. F. Chief executives define their own data needs [J]. Harvard business review, 1979(03).

[4] Zhanglin Wang, Zhenhua Lu, Yuqiang Feng. Foreign evaluation information system success research review [J]. Journal of Harbin industrial university (social science edition), 2010(06):68-73.

[5] DeLone William H. and McLean. Information Systems Success: The Quest for the Dependent Variable [J]. Information Systems Research, 1992, 3(1):60-95.

[6] DeLone William H. and McLean. The DeLone and McLean Model of Information Systems Success: A Ten-Year Update [J]. Journal of Management Information Systems, 2003, 19(4):9-30.

[7] Huijin Wang, Guocheng Liu. COBIT model and its use in micro economic subject information system audit [J]. Journal of auditing research, 2009(01):64-68. 